\title{
PENGARUH TEMPERATUR TERHADAP SIFAT BENDING KOMPOSIT POLIESTER BERPENGUAT SERAT DAUN GEWANG
}

\author{
Kristomus Boimau \\ Teknik Mesin, Universitas Nusa Cendana \\ Kupang, 85228, Indonesia \\ email: kristomus.boimau@staf.undana.ac.id
}

\begin{abstract}
Abstrak
Perilaku sifat mekanik komposit dipengaruhi oleh kondisi lingkungan dimana material itu diaplikasikan, salah satu diantaranya adalah temperatur. Penelitian ini bertujuan untuk mengkaji pengaruh temperatur terhadap sifat bending komposit polyester berpenguat serat pucuk daun gewang. Material yang digunakan dalam penelitian ini adalah resin polyester sebagai matriks dan serat daun gewang sebagai penguatnya. Serat daun gewang diperoleh dari pucuk pohon gewang yang diserut, kemudian dikeringkan dengan sinar matahari. Selanjutnya serat diberi perlakuan alkali 5\% dengan cara direndam selama 30 menit. Fraksi volume serat yang digunakan adalah $32 \%$, sedangkan matrik sebesar 68\%. Komposit hasil cetakan dibentuk menjadi spesimen uji sesuai standar ASTM D790. Sebelum dilakukan pengujian bending, specimen uji dipanasakan dalam dapur/oven listrik selama 1 jam dengan variasi temperature sebesar $100^{\circ} \mathrm{C}, 150^{\circ} \mathrm{C}$ dan $200^{\circ} \mathrm{C}$ kemudian dikeluarkan dan diuji. Hasil pengujian menunjukkan bahwa nilai kekuatan bending komposit yang dipanaskan pada temperature $200^{\circ} \mathrm{C}$ memiliki nilai terendah yakni sebesar $42.8 \mathrm{MPa}$ sedangkan nilai tertinggi sebesar $75.64 \mathrm{MPa}$ diperoleh pada specimen yang dipanaskan pada temperature $100^{\circ} \mathrm{C}$. Hasil foto makro patahan menunjukkan adanya retak kecil pada komposit yang dipanaskan pada temperatur $100^{\circ} \mathrm{C}$, sedangkan specimen uji yang dipanaskan pada temperatur $200^{\circ} \mathrm{C}$ patah menjadi 2 bagian.
\end{abstract}

Kata kunci: Serat Gewang, Temperatur, Bending, Komposit, Poliester

\begin{abstract}
The behavior of the mechanical properties of composites is influenced by environmental conditions where the material is applied, one of which is temperature. This study aims to examine the effect of temperature on the bending properties of polyester composites reinforced with gewang leaf shoot fibers. The material used in this research is polyester resin as a matrix and gewang leaf fiber as a reinforcement. Gewang leaf fiber is obtained from the top of the gewang tree which is shaved, then dried in the sun. Furthermore, the fiber was treated with 5\% alkaline by soaking for 30 minutes. The volume fraction of the fiber used is $32 \%$, while the matrix is $68 \%$. The molded composite was formed into a test specimen according to the ASTM D790 standard. Prior to the bending test, the test specimen was heated in a furnance electric for 1 hour with temperature variations of $100^{\circ} \mathrm{C}, 150^{\circ} \mathrm{C}$ and $200^{\circ} \mathrm{C}$, then removed and tested. The test results showed that the value of the bending strength of the composite heated at a temperature of $200^{\circ} \mathrm{C}$ had the lowest value of $42.8 \mathrm{MPa}$ while the highest value of $75.64 \mathrm{MPa}$ was obtained in the specimen heated at a temperature of $100^{\circ} \mathrm{C}$. The results of the macro photo of the fracture showed small cracks in the composite heated at a temperature of $100^{\circ} \mathrm{C}$, while the test specimen which was heated at a temperature of $200^{\circ} \mathrm{C}$ broke into 2 parts.
\end{abstract}

Keywords:Gewang Fiber, Temperature, Bending, Composite, Polyester 


\section{PENDAHULUAN}

Pencemaran lingkungan dan pemanasan global menjadi isu penting yang mempengaruhi banyak kebijakan pemimpin dunia terhadap konsep pembangunan berkelanjutan (suistanable development), termasuk diantaranya regulasi terkait pengembangan material komposit polimer yang ramah lingkungan dan juga ramah terhadap kesehatan. Hal ini mendorong pelaku dunia industri dan para peneliti berlomba-lomba menemukan material komposit polimer yang limbahnya mudah didaur ulang tanpa harus mencemari lingkungan. Salah satu bukti kongkrit dukungan terhadap pelestarian lingkungan adalah penggunaan serat alam sebagai penguat pada material komposit polimer. $[1,2]$.

Sebenarnya serat alam telah digunakan sejak dahulu kala sebagai penguat struktur material komposit. Namun aplikasi serat alam sebagai bahan pengganti serat sintesis (serat kaca/ fiber glass) pada komposit polimer mulai berkembang pesat pada satu dekade terakhir. Bahkan serat alam mampu menggeser dominasi serat sintesis untuk aplikasi structural maupun nonstruktural. Hal ini disebabkan karena serat alam memberikan banyak keuntungan dibandingkan serat sintesis (fiber glass), seperti biaya produksi yang rendah, tahan terhadap korosi, kontinuitas terjamin karena dapat dibudidaya, kekuatan dan modulus spesifik yang tinggi. [3]

Model analisis data yang lazim digunakan untuk mengkaji perilaku sifat mekanik komposit yang disajikan hingga saat ini didasarkan pada asumsi bahwa material komposit bekerja pada kondisi lingkungan yang konstan (temperatur ruang). Namun dalam aplikasinya, terkadang material tidak bekerja pada kondisi temperatur ruang. Hal ini dapat menyebabkan terjadinya kegagalan konstruksi. Oleh karena itu perlu juga dikaji kemampuan material saat bekerja pada kondisi temperatur yang lebih tinggi atau lebih rendah dari temperatur ruang. [4]

Beberapa kajian pengaruh temperature curing terhadap sifat mekanik komposit polimer berpenguat serat alam (jute) telah diteliti oleh peneliti terdahulu. Suhu curing yang digunakan selama proses pengembangan komposit dimulai dari $160^{\circ} \mathrm{C}, 170^{\circ} \mathrm{C}, 180^{\circ} \mathrm{C}$ dan $190^{\circ} \mathrm{C}$. Hasil berbagai pengujian menunjukkan bahwa nilai kekuatan impak menurun seiring dengan meningkatnya suhu curing, tetapi nilai kekuatan tarik dan lentur cenderung meningkat hingga temperatur $180{ }^{\circ} \mathrm{C}$. Namun pada temperature $190^{\circ} \mathrm{C}$, nilai impak dan kekuatan tariknya menurun. [2]

Peneliti lain juga melakukan kajian dampak temperature terhadap sifat mekanik komposit (GFRP). Spesimen uji tarik diuji pada kondisi temperatur $20^{\circ}, 40^{\circ}, 60^{\circ}, 80^{\circ}$ dan $100^{\circ}$. Hasilnya menggambarkan bahwa kekuatan tarik komposit (GFRP) menurun seiring dengan meningkatnya temperatur, dimana nilai kekuatan tarik tertinggi diperoleh pada specimen yg diuji pada temperature $20^{\circ}$, sedangkan nilai terendah diperoleh pada temperatur $100^{\circ}$. [5]

Kajian pengaruh temperature terhadap nilai beban maksimum (Fmax) dan Kekakuan material thermoplastic berpenguat serat glass juga telah dilakukan. Variasi Temperature yang digunakan adalah, $-20^{\circ}$, $0^{0}, 20^{\circ}, 40^{\circ}, 60^{\circ}, 90^{\circ}, 120^{\circ}$ dan $150^{\circ}$. Hasilnya menunjukkan bahwa beban maksimum (Fmax) dan nilai kekakuan tertinggi diperoleh pada temperature $0^{0}$, sedangkan yang paling rendah diperoleh pada temperature $150^{\circ}$. [6]

Cao et. all [7], melakukan kajian dampak suhu pada $16^{\circ} \mathrm{C}, 30^{\circ} \mathrm{C}, 55^{\circ} \mathrm{C}, 80^{\circ} \mathrm{C}, 120^{\circ} \mathrm{C}$, $160^{\circ} \mathrm{C}$, dan $200^{\circ} \mathrm{C}$ terhadap kekuatan tarik komposit berpenguat serat carbon. Hasilnya menunjukkan bahwa kekuatan tarik komposit serat karbon maksimum diperoleh pada temperatur $16^{\circ} \mathrm{C}$ dan selanjutnya menurun pada temperatur $55^{\circ} \mathrm{C}$ dan cenderung stabil sampai pada temperatur $200^{\circ} \mathrm{C}$

Peneliti lain, Joao Reis [8] telah melakukan kajian pengaruh temperatur terhadap sifat flexural strength komposit polyester mortal dan komposit epoxy mortal. Temperatur pengujian yang digunakan adalah $23^{\circ} \mathrm{C}$, $30^{\circ} \mathrm{C}, 40^{\circ} \mathrm{C}, 50^{\circ} \mathrm{C}, 60^{\circ} \mathrm{C}, 70^{\circ} \mathrm{C}, 80^{\circ} \mathrm{C}$ and 
$90^{\circ} \mathrm{C}$. Hasilnya menunjukkan bahwa sifat flexural strength cenderung menurun seiring dengan meningkatnya temperatur. Nilai flexural strength tertinggi diperoleh pada temperature $23^{\circ} \mathrm{C}$, sedangkan nilai flexural strength terendah diperoleh pada temperatur $90^{\circ} \mathrm{C}$

Dampak temperatur terhadap sifat mekanik komposit epoxy berpenguat serat alam (jute) juga telah diteliti oleh Singh, et all [9]. Material komposit dipanaskan pada temperature $80^{\circ} \mathrm{C}-130^{\circ} \mathrm{C}$, kemudian dilakukan pengujian tarik. Hasil pengujian menunjukkan bahwa kekuatan tarik komposit naik ketika temperature dinaikan hingga $100^{\circ} \mathrm{C}$, namun kekuatan tariknya menurun seiring dengan naiknya temperature perlakuan.

Dengan melihat beberapa kajian terdahulu di atas, maka penelitian ini dilakukan untuk mengkaji pengaruh temperatur terhadap sifat bending komposit polyester berpenguat serat daun gewang.

Serat alam yang digunakan pada penelitian ini berasal dari pohon gewang (Corypha Utan). Pucuk daun tanaman ini biasa digunakan sebagai bahan tali temali, sedangkan daun yang tua digunakan sebagai atap rumah. Pemanfaatan pucuk daun sebagai penguat material komposit diharapkan mampu memberikan nilai tambah bagi tanaman tersebut.
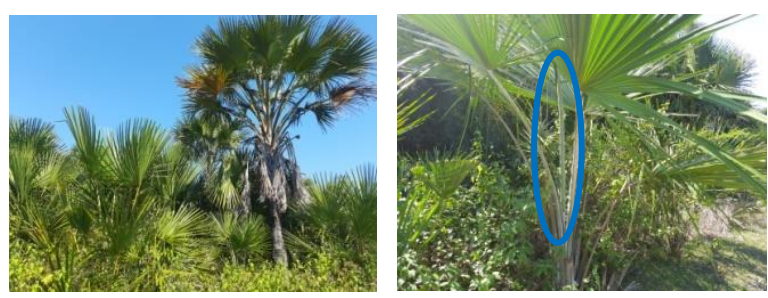

Gambar 1. Pohon Gewang

\section{METODE PENELITIAN}

Bahan yang digunakan dalam penelitian ini adalah resin polyester dan serat dari pucuk/tunas pohon gewang.

Berikut ini prosedur pengolahan pucuk daun gewang menjadi serat.

1. Pengambilan pucuk daun gewang, kemudian pisahkan daun dan lidinya. Selanjutnya daun tersebut diserut dengan pisau untuk memisahkan serat dari kulit daun

2. Serat dipotong dengan ukuran panjang 5 $\mathrm{cm}$.

3. Serat direndam dalam larutan $\mathrm{NaOH} 5 \%$ selama 30 menit, setelah itu serat dikeluarkan dari larutan, kemudian dicuci menggunakan air bersih dan selanjutnya dikeringkan dengan bantuan sinar matahari.

\section{Prosedur pembuatan komposit dan spesimen uji bending}

Komposit merupakan gabungan antara 2 (dua) material yaitu serat daun gewang sebagai penguat dan resin polyester sebagai matriknya.

Proses pembuatan komposit adalah sebagai berikut:

1. Serat ditimbang menggunakan timbangan digital untuk diketahui masanya sesuai dengan fraksi volume serat sebesar $32 \%$.

2. Komposit dicetak dalam cetakan kayu, dengan perbandingan jumlah serat-resin sesuai aturan rule of mixture (RoM). Proses pencetakan menggunakan metode hand ly up, dimana resin dituang ke dalam cetakan, kemudian serat dimasukan ke dalam cetakan, dicampur agar semua serat terbasahi oleh resin, kemudian cetakan dipres/ditekan selama 24 jam. Setelah itu cetakan dibuka.

3. Komposit hasil cetakan dibentuk menjadi specimen uji bending sesuai standar ASTM D790.

\section{ProsedurPengujian Spesimen Uji Komposit.}

Sebelum dilakukan pengujian bending, spesimen uji bending diberikan perlakuan pemanasan (ditempatkan) dalam furnance listrik selama 1 jam, dengan variasi temperature $100^{\circ} \mathrm{C}, \quad 150^{\circ} \mathrm{C}$ dan $200^{\circ} \mathrm{C}$. Setelah 1 jam, specimen uji dikeluarkan dan langsung dilakukan pengujian bending.

Gambaran aktifitas penelitian yang dilakukan, dapat dilihat pada gambar 2 di bawah ini. 


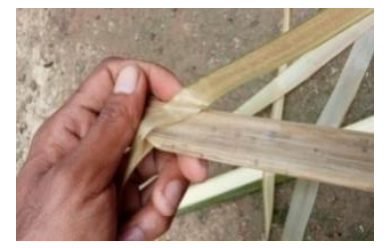

a

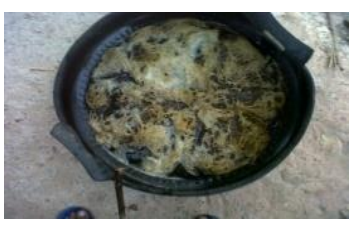

c

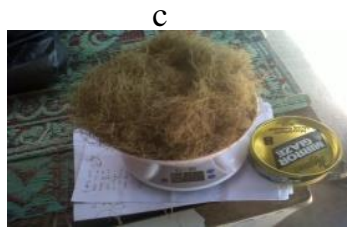

e

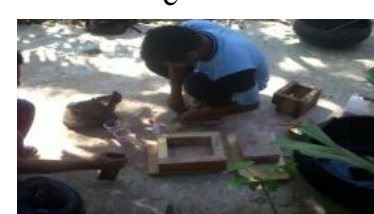

g

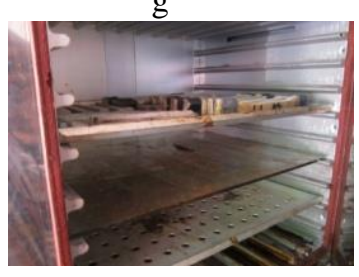

i

Gambar 2.

a. Proses serut pucuk daun gewang

b. Serat pucuk daun gewang hasil serut

c. Proses perlakuan alkali,

d. Pengeringan serat (dijemur) setelah perlakuan alkali,

e. Penimbangan serat (fraksi volume 32\%)

f. Penimbangan matriks (fraksi volume $68 \%$ )

g. Proses pencetakan komposit,

h. Proses press (Penekanan)

i. Pengovenan specimen uji dengan dapur/oven listrik

j. Pengujian Bending dengan alat uji bending

\section{HASIL DAN PEMBAHASAN}

Hasil pengujian bending yang dilakukan, diperoleh data berupa beban dan defleksi. Data ini kemudian digunakan untuk menghitung nilai tegangan bending dan modulus bending, serta ditampilkan dalam bentuk grafik batang.

\section{Tegangan Bending}

Tegangan bending komposit dihitung dengan persamaan berikut:

$$
\sigma_{\mathrm{b}}=\frac{3 \mathrm{P} \mathrm{L}}{2 \mathrm{~b} \mathrm{~d}^{2}}
$$

Selanjutnya hasil perhitungan ditampilkan dalam bentuk grafik seperti pada gambar 3 di bawah ini.

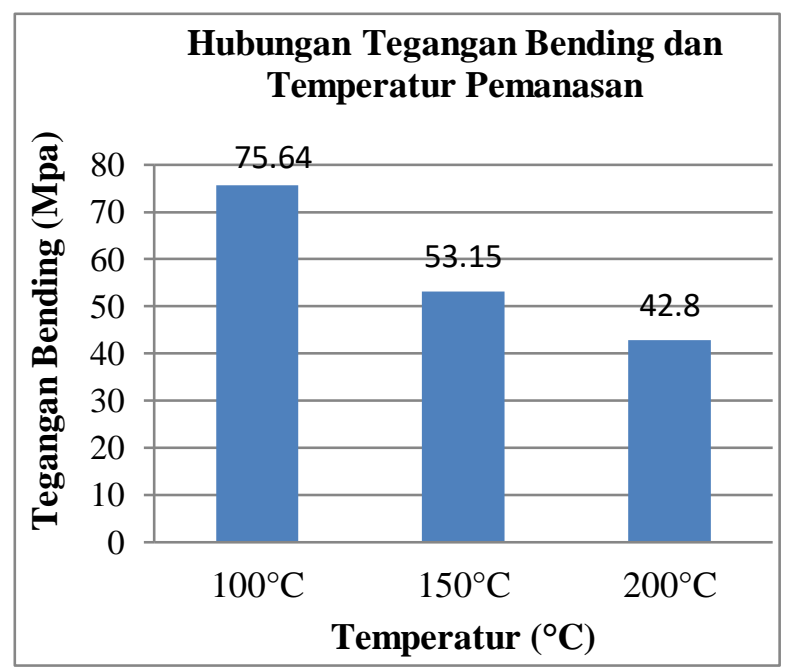

Gambar 3. Hubungan antara Tegangan Bending dan Temperatur Pemanasan Spesimen Uji

Dari gambar 2 di atas menunjukkan bahwa tegangan bending komposit poliester yang diperkuat serat daun gewang mengalami penurunan kekuatan bending seiring dengan meningkatnya temperatur pemanasan. Nilai tegangan bending yang ditampilkan pada gambar merupakan gambaran tegangan bending komposit polyester berpenguat serat pucuk daun gewang yang dipanaskan temperatur $100^{\circ} \mathrm{C}$, $150^{\circ} \mathrm{C}$ dan $200^{\circ} \mathrm{C}$ kemudian diuji. Dari gambar 2 di atas, terlihat bahwa nilai tegangan bending tertinggi diperoleh pada spesimen yang diberikan perlakuan pemanasan dengan temperatur $100^{\circ} \mathrm{C}$ selama 1 jam yaitu sebesar 75,6386 MPa, sedangkan yang paling rendah terdapat pada temperatur $200^{\circ} \mathrm{C}$ yakni sebesar $42,8 \mathrm{MPa}$. Hal ini disebabkan spesimen uji komposit yang terdiri dari matrik poliester (68\%) 
merupakan polimer termoset yang memiliki ikatan kovalen dengan rantai polimernya, atau yang disebut crosslink. Ketika polimer dipanaskan pada temperatur tertentu, ikatan yang putus bukan hanya ikatan antar rantai, tetapi juga ikatan dalam rantainya yang menghubungkan setiap monomernya, sehingga polimer tersebut tidak akan meleleh melainkan akan terdegradasi. Akibat terdegradasi, maka material komposit tidak kuat menahan beban yang diberikan. Dengan adanya ikatan rantai monomer yang putus akibat temperatur yang diberikan, maka ikatan dengan serat pun akan terputus sehingga transfer beban tidak merata ke seluruh bagian dari spesimen uji.

\section{Modulus Bending.}

Nilai modulus bending komposit dapat dihitung dengan persamaan berikut:

$$
\mathrm{E}_{\mathrm{b}}=\frac{\mathrm{L}^{3} \cdot \mathrm{m}}{4 \mathrm{bd}^{3}}
$$

nilai m pada persamaan 2 di atas merupakan gradien garis (kemiringan kurva) antara beban dan defleksi.

Berikut ini adalah contoh untuk memperoleh nilai " $m$ ", dengan cara dibuat slope tegangan pada kurva beban terhadap defleksi.

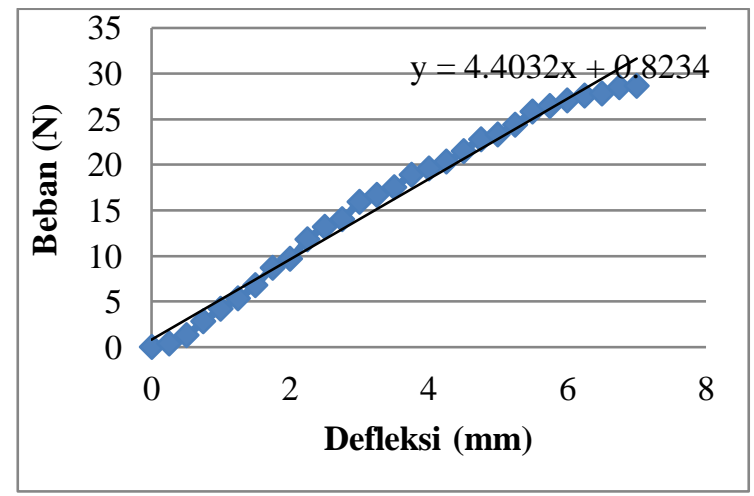

Gambar 4. Grafik hubungan defleksi dan beban pada temperatur $100^{\circ} \mathrm{C}$

Pada gambar 4 di atas, tampak bahwa nilai gradien kemiringan (m) sebesar 4,403. Cara yang sama juga digunakan untuk mencari nilai $m$ untuk spesimen uji yang lain, kemudian nilai ' $m$ ' disubstitusi ke persamaan 2 sehingga dapat diperoleh nilai modulus elastisitas. Selanjutnya ditampilkan dalam bentuk grafik, seperti tampak pada gambar 5 di bawah ini.

Pada gambar 5 terlihat bahwa komposit poliester berpenguat serat pucuk daun gewang pada temperatur $100^{\circ} \mathrm{C}$ memiliki nilai modulus elastisitas bending yang paling tinggi sebesar 261,435 MPa dan yang paling rendah terdapat pada temperatur $200^{\circ} \mathrm{C}$ dengan nilai sebesar $212,92 \mathrm{MPa}$. Hal ini menggambarkan suatu kondisi dimana material komposit bermatrik poliester (thermosetting), mengalami degradasi akibat dari kondisi lingkungan (temperatur yang tinggi) sehingga kekakuannya menurun. Hal ini disebabkan karena adanya rantai monomer yang putus akibat temperatur yang tinggi tersebut. Peningkatan temperatur mengakibatkan menurunnya nilai modulus elastisitas komposit secara keseluruhan.

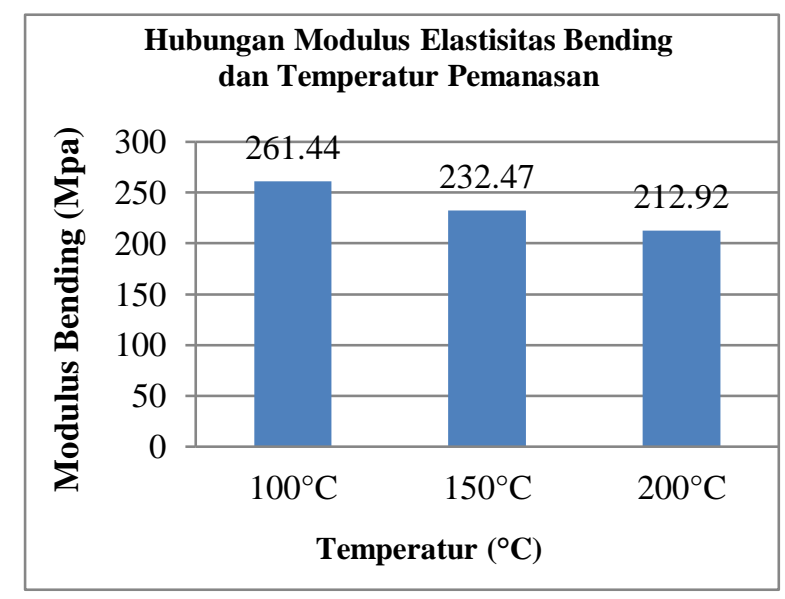

Gambar 5. Hubungan antara Modulus Elastisitas Bending dan Temperatur Pemanasan Spesimen Uji

\section{Foto Makro Patahan}

Pengujian three point bending yang dilakukan, menyebabkan specimen uji menjadi retak dan patah, seperti tampak patah gambar 6 di bawah ini. 


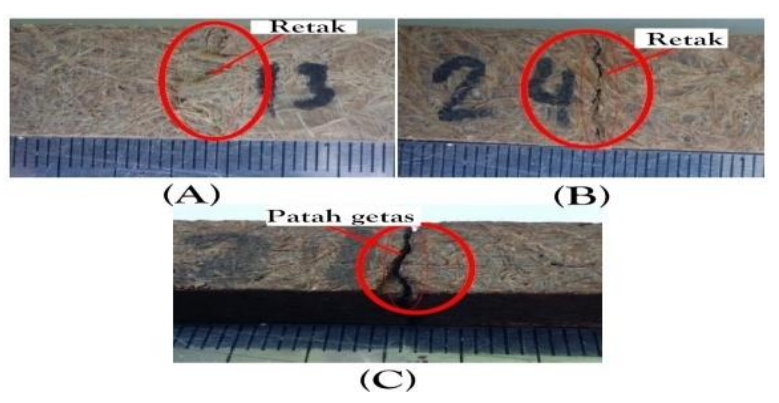

Gambar 5. Penampang patah spesimen uji komposit polister berpenguat serat daun gewang yang dipanaskan pada temperatur (a). $100^{\circ} \mathrm{C}$, (b). $150^{\circ} \mathrm{C}$, (c). $200^{\circ} \mathrm{C}$

Dari gambar 6 di atas terlihat bahwa spesimen uji dengan pemanasan pada temperatur $200^{\circ} \mathrm{C}$ mengalami patah dengan alur patahan tanpa ada serat yang tercabut (fiber pullout). Hal ini menunjukkan bahwa ikatan antara serat dan matrik sangat kuat, namun akibat pemanasan yang diberikan menyebabkan matrik mengalami degradasi yang cukup serius. Sebaliknya pada specimen uji yang diberikan pemanasan dengan temperature $100^{\circ} \mathrm{C}$ tidak mengalami patah, namun hanya terjadi retak kecil. Sedangkan specimen uji dengan temperatur $150^{\circ}$ mengalami retak yang cukup besar namun tidak sampai patah menjadi 2 bagian.

\section{KESIMPULAN}

Dari uraian hasil penelitian yang diperoleh, dapat disimpulkan bahwa temperatur memberikan dampak terhadap kekuatan bending komposit, dimana semakin tinggi tinggi temperature maka kekuatan bending cenderung menurun.

\section{REFERENSI}

[1] Pramendra Kumar Bajpai, Inderdeep Singh and Jitendra Madaan, Development and characterization of PLA-based green composites: A review', Journal of Thermoplastic Composite Materials, 2012

[2] Sehijpal Singh Khangura, Jai Inder Preet Singh, Vikas Dhawan, 'Effect of Curing Temperature on Mechanical Properties of Jute Fiber Reinforced Polylactic Acid Based Green
Composite', International Journal of Industrial and Manufacturing Engineering, Vol:12, No:9, 2018

[3] Palla Hari Sankar, Y. V. Mohana Reddy, K. Hemachandra Reddy, M. Ashok Kumar, A. Ramesh, 'The Effect of Fiber Length on Tensile Properties of Polyester Resin Composites Reinforced by the Fibers of Sansevieria trifasciata', International Letters of Natural Sciences, Vol. 8, pp 7-13, 2014.

[4] Ronald F. Gibson, Principles of Composite Material Mechanics, Fourth Edition, CRC Press, Taylor \& Francis Group, Boca Raton London New York, 2016, pp 191-193.

[5] J. L. V. Coelho and J. M. L. Reis, Effects of Strain Rate And Temperature on The Mechanical Properties of GFRP Composites, Engenharia Térmica (Thermal Engineering), Vol. 10, No. 01 - 02, p. 03-06, 2011.

[6] L Cadieu, J B Kopp, J Jumel, J Bega and $\mathrm{C}$ Froustey, Temperature Effect On The Mechanical Properties And Damage Mechanisms Of A Glass/Thermoplastic Laminate, Journal of Composite Materials, Sage Publication, 2019

[7] Shenghu Cao, Zhishen Wu And Xin Wang, Tensile Properties of CFRP and Hybrid FRP Composites at Elevated Temperatures, Journal of Composite Materials, Vol. 43, No. 04, Sage Publication, 2009.

[8] João Marciano Laredo dos Reis, Effect of Temperature on the Mechanical Properties of Polymer Mortars, Journal Materials Research, Vol. 15, No. 4, p645-649, 2012.

[9] Jai Inder Preet Singh, Sehijpal Singh and Vikas Dhawan, Effect of Curing Temperature on Mechanical Properties of Natural Fiber Reinforced Polymer Composites, Journal of Natural Fibers, 2017 